\title{
Pesticides and bees
}

\author{
Laura Maxim \& Gérard Arnold
}

I n May 2013, the European Commission (EC) adopted a 2-year restriction on the use of three neonicotinoid pesticides clothianidin and imidacloprid, both produced by Bayer, and thiametoxam, produced by Syngenta - on crops that attract bees and other pollinators to protect declining populations of pollinating bees. The decision was based on a risk assessment by the European Food Safety Authority (EFSA) [1]. In August 2013, the two companies sued the EC. Syngenta claims the decision was based on a flawed process, on an inaccurate and incomplete EFSA assessment, and was made without the full support of the EU Member States.

The EFSA assessments focused on three main routes by which bees could be exposed to the pesticides: from residues in nectar and pollen in the flowers of treated plants; from dust produced when treated seeds are sown or granules are applied; and from residues in guttation fluid produced by treated plants. They found risks in all three cases.

The result differed from previous risk assessments of these pesticides for two main reasons. First, EFSA considered recommendations from a Scientific Opinion on the science behind a guidance document on pesticide risk assessment for bees [2]. The Opinion recommends that the risks should be assessed more comprehensively, and outlines the scientific weaknesses of the current guidelines. EFSA scientists also evaluated both the data originally submitted for approval of these products at the EU and Member State levels, and the abundant scientific literature published since 2000, which indicates sublethal and acute toxic effects of the three pesticides on honeybees, bumblebees and solitary bees $[3,4]$. Recent reviews conclude that at realistic doses, neonicotinoids can cause a wide range of adverse sublethal effects in honeybee colonies. These include impairments to foraging success, brood and larval development, olfactory memory, learning, flying behavior, and navigation capacity. The toxicity of the pesticides can be amplified by infectious agents such as Nosema ceranae. In bumblebees, field realistic levels of imidacloprid have been shown to impair queen production, growth rate, and pollen foraging efficiency $[3,4]$. Acute toxicity has led to massive colony losses in Italy, Germany, Austria and Slovenia during neonicotinoid seeddressed corn sowing [3].

In general, there are two main scientific weaknesses of the way regulatory testing is currently done. First, when new products with new properties and potentially new risks enter the market, old methodological frameworks for risk assessment may be inadequate. This is true for systemic neonicotinoids, and in particular those used in seed-dressing and granules: the risks to honeybees have new characteristics, such as extended colony exposure through contaminated pollen and nectar, acute toxicity through dust, and very high toxicity at very low dose. However, these characteristics were overlooked during the risk assessment for marketing authorization, which used old methodological frameworks developed for sprayed pesticides.

Second, the risk assessments used to bring the three pesticides to market were based on guidelines with several methodological weaknesses. Field tests in particular have a decisive role: a pesticide can be marketed if field studies do not find effects, even if lab studies do. But major weaknesses have recently been identified in the current guidelines for field testing in relation to bees: low surface area of the test field, small colony sizes, and very small distances between the hives and the treated field. This leads to uncertainties about the real exposure levels [2].

The consequences of an inappropriate risk assessment could be significant: neonicotinoids are the most widely used class of insecticides, with a global market share of more than $25 \%$ [3]. Imidacloprid is the second most widely used (2008) agrochemical in the world.

The response of the companies involved to the EC's decision is not unprecedented. In
1999, a French Minister of Agriculture was sued by Bayer for having restricted the use of imidacloprid in sunflower seed-dressing. The French Conseil d'Etat decided in the Minister's favor. Syngenta and Bayer's recent legal action confirms their uncompromising response to risks associated with marketed products.

In this confrontational context, the adaptation of regulations is, unsurprisingly, very slow. In France, the first signs of honeybee decline came in 1995; the first restriction of imidacloprid in sunflower seed-dressing was in 1999 and in maize seed-dressing in 2004; the conclusion of a French expert committee came in 2003. However, it was not until 2012-13 years after the first restriction of a systemic neonicotinoid in France-that EFSA stressed the need to improve standardized tests in Europe. These new tests are only in a preliminary discussion phase; hopefully it will not take several more years.

\section{Conflict of interest}

The authors declare that they have no conflict of interest.

\section{References}

1. EFSA (2013) Press release, EFSA Identifies Risks to Bees from Neonicotinoids. Parma, Italy: European Food Safety Authority

2. EFSA (2012) EFSA J 10: 2668

3. Van der Sluijs J, Simon-Delso N, Goulson D, Maxim L, Bonmatin J-M, Belzunces LP (2013) COSUST 5: 293-305

4. Goulson D (2013) J Appl Ecol 50: $977-987$

Laura Maxim is at the Institut des Sciences de la Communication du CNRS, Gif-sur-Yuette, France. Gérard Arnold is at the Laboratoire Évolution, Cénomes et Spéciation, Gif-sur-Yuette, France Email: laura.maxim@iscc.cnrs.fr

DOI 10.1002/embr.201338218 